\title{
Are there specific health-related factors that can accentuate the risk of suicide among men with prostate cancer?
}

\author{
Abraraw Lehuluante • Per Fransson \\ Received: 6 November 2013 / Accepted: 28 January 2014 / Published online: 11 February 2014 \\ (C) The Author(s) 2014. This article is published with open access at Springerlink.com
}

\begin{abstract}
Purpose The aim of this study was to explore if there were some specific factors pertinent to health-related quality of life (HRQoL) that could affect self-experienced suicide ideation in men with prostate cancer (PCa).

Methods Questionnaires containing 45 items were distributed to members of the Swedish Prostate Cancer Federation in May 2012. Out of 6,400 distributed questionnaires, 3,165 members (50 \%) with PCa completed the questionnaires. Those members expressed their experienced HRQoL and experienced suicide ideation using VAS-like scales as well as multiplechoice questions. Both descriptive and analytical statistical methods were employed. A regression model was used to explore the relationship between experienced health-related quality of life and experienced suicide ideation.

Results Generally, the respondents rated their selfexperienced health-related quality of life as good. About $40 \%$ of the participants had experienced problem with incontinence, and $23 \%$ had obstructions during miction. About $7 \%$ of the respondents experienced suicidal ideation, at least sometime. The regression model showed statistically significant relationships between suicide ideation, on the one hand, and lower self-rated health-related quality of life $(P<0.001)$, physical pain $(P=0.04)$, pain during miction $(P=0.03)$, and low-rated mental/physical energy $(P=0.03)$, on the other. Conclusion It is quite necessary to know which specific disease and treatment-related problems can trigger suicide ideations in men with prostate cancer and to try to direct treatment, care, and psychosocial resources to alleviate these problems in time.
\end{abstract}

A. Lehuluante $\cdot$ P. Fransson $(\triangle)$

Department of Nursing, Umeå University, SE-901 87 Umeå, Sweden

e-mail: Per.Fransson@nurs.umu.se

A. Lehuluante

e-mail: able0002@student.umu.se
Keywords Suicide $\cdot$ Prostate cancer $\cdot$ Health-related quality of life $\cdot$ Suicide ideation

\section{Introduction}

In Sweden, prostate cancer $(\mathrm{PCa})$ is the most common form of cancer, accounting for $36 \%$ of all disease incidents and $32 \%$ of all male cancers in 2011 [1, 2] Approximately 10,000 men get the diagnosis every year, and PCa has had an annual increasing rate of $2 \%$ for the past 20 years [3]. Treatment options offered to patients depend on factors such as age and disease progress. The first-line treatment strategy for patients with a remaining life expectancy of 10-20 years has been active surveillance that involves frequent PSA level tests and occasional biopsies. Prostatectomy or radiotherapy is recommended for those with a remaining life expectancy of more than 20 years [1]. Curative treatment, which involves one of the various prostatectomy or radiotherapy techniques, is recommended only if the tumor is localized [1]. These Swedish therapy recommendations are in line with the European Association of Urology (EAU) guidelines for PCa treatment [2].

Suicidal ideation is a multifaceted and multicausal phenomenon. It can be triggered by causes that may have genetically, psychological, and/or neurobiological factors [4, 5]. For example, concordance rate for death by suicide was found to be higher in monozygotic than dizygotic twins [5]. A family history of suicide can increase the risk of committing suicide by twofold [5]. The probability of developing suicidal ideation was found to be higher in people with psychopathological problems such as major depression and substance abuse [5]. It has been long known that stressors can lead to a higher production of stress hormones that can negatively affect mineralocorticoid and glucocorticoid receptors in the brain, in general, the hypothalamic-pituitary-adrenal (HPA) axis in particular $[4,5]$. The latter is a neuroendocrine system that 
regulates the body's response to stress and an imbalance in this system can cause mood disorders including suicidal ideation $[4,5]$. Cancer patients can be affected, among others, by the mental and physical demands of having the diagnosis as well as stressors that have to do with disease progress and treatment [6].

Although the degree of disease progress is central to symptom-giving and disease-related health problems, $\mathrm{PCa}$ can cause hematuria, urinary obstruction, and edema from regional lymphatic obstruction, pain from bone metastasis, sexual dysfunction, and impaired bowel function. It can also cause general physical impairments and impairment in playing social roles $[7,8]$. Not only the disease but also its treatment can cause health problems. Treatments such as androgen deprivation, radical prostatectomy, and radiotherapy caused urinary, bowel, or sexual dysfunction $[9,10]$. Although the frequency, duration, and severity of these treatment-related health problems can vary from one treatment option to the other, no conclusive evidence has been found that could make one treatment option better than the other $[10,11]$.

The diagnosis as well as disease- and treatment-related health problems can affect the health-related quality of life (HRQoL) of men with PCa. HRQoL in PCa can also be influenced by factors such as tumor level, time elapsed since diagnosis, individual factors such as educational level and social background, age at diagnosis, and treatment type [8, 12, 13]. For example, patients with stage I tumor exhibited higher HRQoL scores compared to those with tumor stage IV [12]. Men with advanced PCa face severe and several healthand treatment-related problems compared with men with localized PCa [14]. Research has shown that after baseline similarities with controls (i.e., men without PCa diagnosis), men with $\mathrm{PCa}$ experienced significant deteriorations in physical, mental, and social aspects of their lives, especially 6 months following diagnosis. However, men who were surveyed beyond 1 year after diagnosis had similar scores of HRQoL to those of controls $[15,16]$. Increased risk for major depressive disorder was observed among men who received either conservative management or external beam radiation [15].

Several studies have shown that suicide ideation and incidents of suicide are higher in cancer patients in general and in patients with $\mathrm{PCa}$ in particular. Although suicidal ideation does not necessarily result in completed suicide, its prevalence in cancer patients was found to be higher compared to that in the general population [17]. The risk and incidence of suicide in people with a cancer diagnosis is approximately double the incidence of suicide in the general population [18]. The risk and incidence of suicide among men with PCa has been also found to be high $[19,20]$. Men with newly diagnosed PCa as well as metastatic disease were found to be higher risk groups [20-23]. Poorly controlled pain management, advanced stage of cancer, being foreign-born, recent diagnosis, increased physical impairment, and certain chemotherapeutic treatments have been found to be related to an increased risk of suicide $[20,21,24]$. Even though depression has been singled out as a major risk factor for suicide, other factors such as family discord and lack of social support have been implicated with suicide in patients with $\mathrm{PCa}$ [25]. Some studies suggest that getting the diagnosis following a PSA screening made patients more susceptible to suicide, while others suggest that it was the disease progress itself that could make patients more susceptible to suicide $[25,26]$.

Men with PCa belong to patient groups that need continuous support. Patient associations that provide opportunities for patients to support each other and get support from without have become increasingly common in Western Europe [27]. The Swedish Prostate Cancer Federation (SPCF) has been instrumental not only in mobilizing and utilizing patients' own resources but also in providing information about $\mathrm{PCa}$ and treatment options, etc. It augments its achievements by encouraging relatives, the Swedish public, as well as interested individuals to join its efforts [28].

As indicated earlier, research literature has shown the effects of health- and disease-related problems on HRQoL. However, there is scantiness in research regarding specific health-related factors that can affect suicide ideation in men with PCa. The aim of this study was, therefore, to explore the relationships between self-experienced HRQoL and selfexperienced suicide ideation in men with PCa diagnosis.

\section{Methods}

\section{Method of data collection}

The SPCF is a national patient federation currently consisting of over 7,500 members comprising people with PCa diagnosis, family members/relatives to those who have the diagnosis, and individuals who join the federation to contribute to better support and care for patients with PCa. In May 2012, questionnaires were distributed to all members of the SPCF6,389 at the time - for the data collection.

Instrument

HRQoL and suicide ideation were evaluated with a selfreported questionnaire. This questionnaire was developed in cooperation with the authors and SPCF. The questionnaire was based on some items from a previously reported validated self-reported questionnaire [16].

The distributed questionnaires contained a total of 45 items that were intended to collect information such as HRQoL as experienced and rated by the participants themselves. Some items were using VAS scales with scores ranging from 0 to 10 (lowest to highest); some items were using four graded verbal 
scales: "none," "sometimes," "often," and "always;" and some items were using "Yes" or "No" answers.

The evaluation of suicide ideation was based on the question "Have you since diagnosis had suicidal thoughts?" with the answer alternatives none, sometimes, often, and always. Moreover, multiple-choice questions were used in order to map out how frequently participants faced health-related mental and physical problems. The questionnaires also contained specific questions about how members felt about their membership in the association (i.e., the SPCF). These questions and their answers were not analyzed and included in this study.

Data analysis

Collected data was analyzed using both descriptive and analytical statistical methods. Descriptive statistical methods were used to describe participant characteristics as well as to present the way participants express and rate their situations of health and illness. A regression model was used to explore the relationship between suicide ideation on the one hand and factors that could have affected HRQoL on the other. IBM SPSS statistics, version 21 (IBM, Armonk, NY, USA) was used for all statistical analyses.

\section{Ethical considerations}

Permission to perform the study was given by the Ethics Committee of the Faculty of Medicine at the Umea University, Sweden, registered as Issue No. (Dnr) 2012-15031M.

Members of the Swedish Prostate Cancer Federation participated in this study with consent.

\section{Results}

The median age of the participants was 73 years (41-95 years). Most of them ( $87 \%$ ) lived in some form of partnership. The majority of the participants had completed elementary school, and most of them had received their PCa diagnosis during and after the year 2000. Most of them had localized PCa at diagnosis (Table 1 ).

Out of the 6,389 distributed questionnaires, 3,512 were returned $(55 \%)$. Of these 6,389 distributed questionnaires, 3,165 members reported that they had had a PCa diagnosis $(49.5 \%)$, and these are included in the actual analysis. Descriptive analyses of collected data (Table 2) had shown that most of the respondents rated the level of their physical and mental energy as higher and their self-experienced quality of life as well as their general health situation as good ( 8 and above on the VAS scale). They rated their experiences of pain due to cancer as lower, but the majority of them rated their
Table 1 Participant characteristics

Participants $(n=3,165)$

$\begin{array}{ll}\text { Age (years) } & 73 \\ \text { Median } & 41-95 \\ \text { Range } & \\ \text { Marital status, no. (\%) } & 2,525(80) \\ \text { Married/have relation } & 501(16) \\ \text { Unmarried/no relation/widow } & 139(4) \\ \text { Missing } & \\ \text { Education (\%) } & 1,213(38) \\ \text { Elementary school } & 886(28) \\ \text { High school } & 937(30) \\ \text { Higher education } & 129(4) \\ \text { Missing } & \\ \text { Years since diagnose (years) } & 6.0 \\ \text { Median } & 0-50 \\ \text { Range } & \\ \text { Disease status }{ }^{\mathrm{a}}(\%) & 2,563(81) \\ \text { Local disease } & 392(12) \\ \text { Locally advanced } & 95(3) \\ \text { Spread disease } & 51(4) \\ \text { Missing/not known } & \end{array}$

${ }^{\mathrm{a}}$ Data not verified from medical records

level of sexual activity as well as non-medicated erectile function as lower.

Participants generally experienced the frequencies of their disease-induced physical symptoms as lower (Table 3). About $40 \%$ of the participants had sometimes experienced problem with urinary incontinence, and about $23 \%$ had experienced obstruction during miction.

The frequency of symptoms of anxiety and depression was mixed. The number of respondents who sometimes or often experienced such mental symptoms was higher than the number of those who did not. About $7 \%$ of the respondents reported that they had sometimes experienced suicidal

Table 2 Self-rated physical and psychic condition

\begin{tabular}{lll}
\hline & No. & Median (SD) \\
\hline Energy level $^{\mathrm{a}}$ & 3,115 & $7.0(2.2)$ \\
Health status $^{\mathrm{a}}$ & 3,052 & $8.0(3.4)$ \\
Quality of life $^{\mathrm{a}}$ & 3,118 & $7.0(2.1)$ \\
Pain caused by PCa $^{\mathrm{b}}$ & 3,105 & $0.0(1.9)$ \\
Sexual desire $^{\mathrm{a}}$ & 3,098 & $4.0(3.3)$ \\
Sexual activity $^{\mathrm{a}}$ & 3,105 & $0.0(2.9)$ \\
Erection function & 3,100 & $0.0(2.8)$ \\
\hline
\end{tabular}

${ }^{a}$ Higher value represents higher function/better condition on the scale graded from 0 to 10

${ }^{\mathrm{b}}$ Higher value represents more pain 
Table 3 Frequency of self-rated somatic and psychic symptoms

\begin{tabular}{llllll}
\hline Symptom & \multicolumn{3}{l}{ Frequency } & & \\
\cline { 2 - 6 } & $n$ & $\begin{array}{l}\text { Never } \\
(\%)\end{array}$ & $\begin{array}{l}\text { Sometimes } \\
(\%)\end{array}$ & $\begin{array}{l}\text { Often } \\
(\%)\end{array}$ & $\begin{array}{l}\text { Always } \\
(\%)\end{array}$ \\
\hline Urinary incontinence & 2,923 & 37 & 41 & 8 & 7 \\
Urinary obstruction & 2,596 & 47 & 23 & 7 & 5 \\
Hematuria & 2,463 & 71 & 5 & 1 & 1 \\
Pain during miction & 2,470 & 69 & 7 & 1 & 1 \\
Stool leakage & 2,601 & 64 & 15 & 2 & 1 \\
Anxiety/depression & 3,120 & 46 & 46 & 5 & 1 \\
Suicide ideation & 3,113 & 93 & 7 & 0.3 & 0.1 \\
\hline
\end{tabular}

ideation on the item "Have you since diagnosis had suicidal thoughts?"

Being consistent with the way they rated using the VAS scale, the majority of the participants indicated that they had little or no pain during miction.

Analytical statistics done by using a regression model indicated that there were statistically significant relations $(P \leq 0.05)$ between suicide ideation on the one hand and lower self-rated quality of life $(P<0.001)$, the experience of physical pain $(P \leq 0.04)$ and pain during miction $(P=0.03)$, and lowrated mental and physical energy $(P=0.03)$. Low-rated sexual function had no statistically significant relationship with suicide ideation. However, the analysis shows that there was a nearly significant relationship $(P=0.06)$ between them.

Psychosocial and demographic factors were also found to have statistically significant relationships with suicide ideation. The younger the age, the higher is the degree of suicide ideation $(P<0.001)$. Being unmarried/not living in some kind of partnership was also found to have a statistically significant relationship with suicide ideation (Table 4).

\section{Discussion}

The aim this study was to explore the relationships between self-experienced HRQoL and self-experienced suicide ideation in persons with a PCa diagnosis. As indicated above, respondents generally experienced the severity and frequency of their disease-induced somatic symptoms as lower. The results of this study are in line with an earlier Swedish study

Table 4 Factors associated with suicide ideation

\begin{tabular}{lcr}
\hline Factor & Std. coefficient $\left(R^{2}=0.364\right)$ & $P$ value \\
\hline Marital status & 0.046 & 0.026 \\
Anxiety/depression & 0.266 & $<0.001$ \\
Pain caused by PCa & 0.053 & 0.020 \\
Quality of life & -0.117 & 0.001 \\
\hline
\end{tabular}

that showed similar results with regard to how men with $\mathrm{PCa}$ saw their HRQoL [27].

Our study has shown that problems associated with incontinence were related to lower rates of HRQoL. This confirms earlier studies that indicated an association between problems with urinary continence and low-rated quality of life. According to a recent study, elderly PCa survivors had a two- to fivefold greater prevalence of incontinence that worsened with time, compared to their peers in the general population [29]. Some treatment options, such as brachytherapy, have been associated with urinary, bowel, and sexual symptoms [30]. Problems associated with urinary function of the male partner have been implicated in affecting the sexual life of female partners [31].

Another problem that was experienced by respondents was depression and anxiety. The findings of this study are in line with earlier studies that found a higher rate of depression and anxiety in persons with a PCa diagnosis [30]. The prevalence of psychological distress among cancer patients is said to be higher, and the degree increases with advances in disease progress and poor prognosis [32-34]. Since anxiety and depression can occur before (during the process of screening) and at any point after the diagnosis, early detection and treatment of these psychological stressors is highly recommended [32, 35, 36]. A recent Swedish study has shown that men with PCa had an increased risk of requiring psychiatric treatment for depression or posttraumatic stress disorder, compared to age-matched controls. Severe anxiety disorders were associated with advanced stage PCa [37].

Even if it is difficult to reach a general conclusion without at least knowing the level of disease progress, the types of treatment that the majority of the participants went through, etc., the fact that participants had lesser complaints regarding the most common PCa-related symptoms can be indicative of the quality and effectiveness of Swedish oncological care and treatment in alleviating somatic problems. The results could also be indicators of the one sidedness of oncological care, namely, the emphasis on physical rather than mental problems. Historically, psychosocial care for cancer patients has seldom been seen as an aspect of quality of care [34, 38]. The focus on somatic care as paramount can entail the risk of prolonging life without bothering about whether there is some quality in that life or not [39].

The results of this study show that there were statistically significant relations between suicide ideation on the one hand and lower self-rated quality of life, the experience of physical pain and pain during miction, and low-rated mental and physical energy. In other words, participants who had suicide ideation might have had those physical and mental problems. Even if low-rated sexual function did not have a statistically significant relationship to suicide ideation, the near-significant relationship is indicative of the fact that those who had suicide ideation might have had problems in their sexual life. In fact, 
research had indicated that $\mathrm{PCa}$ patients worry about their sexual lives more than their partners do [40]. Suicide ideation was found to be about $7 \%$ and varied in frequency (i.e., ranging from experiencing suicide ideation sometimes to having the experience often). Despite the relatively low rate of suicide ideation and nuances in the recurrence of suicide ideation, the results of this study are indicative of the existence of the risk of losing one's life. Among the respondents, over 200 men had had suicide ideation at least sometimes.

These figures were results of the self-experience in suicide ideation as expressed by the respondents and estimated only by using a VAS scale. These authors believe that further studies that use more objective means and valid and reliable measuring instruments of suicide ideation can show larger figures than those revealed by this study.

This study has some limitations, for the first, we do not know if suicide attempts were made among the responders. Since this is a study of members from a prostate cancer association, we did not collect individual information regarding this type of information. We did neither collect any information from medical journals confirming this type of information nor information about the disease or treatment. Secondly, the questionnaire has not been validated. The authors in cooperation developed it with the members in the prostate cancer association (SPCF). However, these items were included in the questionnaire since both the patients (members) and researchers thought that these are very important items and there is a lack of this type of information among this group of men with prostate cancer. The aim of the study and development of the questionnaire was not to add a new questionnaire for screening for a risk group of suicide attempt, but to give information of the frequency of suicide ideation in a population of prostate cancer survivors.

To our knowledge, this is the first study in which men with a PCa diagnosis expressed their feelings concerning suicide and the first of its kind to pinpoint specific health problems that could have contributed to or exacerbated suicidal ideation.

Research on suicide shows that suicidal ideation can range from transient thoughts about committing suicide to more severe, ruminative thoughts about it [24]. The more recurring the ideation, the more likely the act of suicide will take place. Here again, depression and anxiety play greater roles in driving patients towards suicide ideation [24].

Early detection of this problem is quite necessary to prevent the loss of life that could well have sociopsychological resonances far and beyond the individuals who have lost their lives [41]. Some of the contributing factors for suicide in the elderly include a lack of social support (i.e., social isolation, being divorced, widowed, or single), psychiatric problems (among others, anxiety and depression), as well as a lack of a sense of coherence to cope with a malignant disease and all its consequences [41, 42]. The relationship between sociodemographic factors and suicide ideation has been implied by this study. The results of this study imply that a relatively younger age and having no partner have a statistically significant relationship with suicide ideation. Oncological care, especially oncologic nursing, needs to include assessing, identifying, and providing the necessary help for patients with suicidal ideation [42, 43]. Although research in the area of psychosocial interventions has been far from conclusive, cognitive behavioral and psycho-educational interventions appear to have been helpful in promoting better psychological adjustment and quality of life for men with prostate cancer. Coping skills training for both patients and spouses is also said to improve the quality of life for both partners [42].

\section{Conclusions}

The significant relationship between specific aspects of HRQoL and suicide ideation implies the need to target and address such aspects of health problems so as to reduce the risk of suicide. Relatively younger patients living without some kind of partnership seem to be the most vulnerable and as such in need of special focus from care providers. Early detection of suicidal tendencies is advisable as much as putting emphasis on detecting and treating depression in men with PCa diagnosis.

Acknowledgement This study was supported by grants from Prostatacancerförbundet and the Research Foundation of the Department of Oncology, University of Umeå.

Conflict of interest The authors have no other relationships/conditions/ circumstances that present potential conflict of interest.

Open AccessThis article is distributed under the terms of the Creative Commons Attribution Noncommercial License which permits any noncommercial use, distribution, and reproduction in any medium, provided the original author(s) and the source are credited.

\section{References}

1. National Prostate Cancer Register (NPCR). National quality report for the year of diagnosis 2011. (2011) http://www.mkmedia.se/ kunder/suf/sites/default/files/pagefiles/20121107_NPCR_Rapport 2011.pdf. Accessed 24 Aug 2013.

2. Swedish National Board of Health and Welfare (NBHW) and the Swedish Association of Local Authorities and Regions (SALAR). Quality and efficiency in Swedish health care - regional comparison 2011. Art. no: 2012-3-15. ISBN 978-91-7164-784-9.

3. The Swedish National Board of Health and Welfare. Cancer incidence in Sweden 2011. ISBN 978-91-7555-003-9. Article No. 2012-12-19.

4. Pompili M, Serafini G, Innamorati M, Möller-Leimkühler AM, Giupponi G, Girardi P, Tatarelli R, Lester D (2010) The hypothalamic-pituitary-adrenal axis and serotonin abnormalities: a selective overview for the implications of suicide prevention. Eur Arch Psychiatry Clin Neurosci 260(8):583-600 
5. Joiner TE Jr, Brown JS, Wingate LR (2005) The psychology and neurobiology of suicidal behavior. Annu Rev Psychol 56:287-314

6. Walker J, Waters RA, Murray G, Swanson H, Hibberd CJ, Rush RW, Storey DJ, Strong VA, Fallon MT, Wall LR, Sharpe M (2008) Better off dead: suicidal thoughts in cancer patients. J Clin Oncol 26(29): 4725-4730

7. Ilic D, Neuberger MM, Djulbegovic M, Dahm P (2013) Screening for prostate cancer (2013). Cochrane Database Syst Rev 1, CD004720

8. Namiki S, Arai Y (2010) Health-related quality of life in men with localized prostate cancer. Int J Urol 17(2):125-138

9. Fransson P, Damber JE, Widmark A (2009) Health-related quality of life 10 years after external beam radiotherapy or watchful waiting in patients with localized prostate cancer. Scand J Urol Nephrol 43:119126

10. Johansson E, Steineck G, Holmberg L, Johansson JE, Nyberg T, Ruutu M, Bill-Axelson A, SPCG-4 Investigators (2011) Long-term quality-of-life outcomes after radical prostatectomy or watchful waiting: the Scandinavian Prostate Cancer Group-4 randomised trial. Lancet Oncol 12:891-899

11. Wilt TJ, MacDonald R, Rutks I, Shamliyan TA, Taylor BC, Kane RL (2008) Systematic review: comparative effectiveness and harms of treatments for clinically localized prostate cancer. Ann Intern Med 148:435-448

12. Vanagas G, Mickeviciene A, Ulys A (2013) Does quality of life of prostate cancer patients differ by stage and treatment? Scand J Public Health 41:58-64

13. Huang GJ, Sadetsky N, Penson DF (2010) Health related quality of life for men treated for localized prostate cancer with long-term follow up. J Urol 183:2206-2212

14. Chambers SK, Pinnock C, Lepore SJ, Hughes S, O'Connell DL (2011) A systematic review of psychosocial interventions for men with prostate cancer and their partners. Patient Educ Couns 85:e75-e88

15. Reeve BB, Stover AM, Jensen RE, Chen RC, Taylor KL, Clauser SB, Collins SP, Potosky AL (2012) Impact of diagnosis and treatment of clinically localized prostate cancer on health-related quality of life for older Americans: a population-based study. Cancer 118: 5679-5687

16. Fransson P, Lund JA, Damber JE, Klepp O, Wiklund F, Fosså S, Widmark A, Scandinavian Prostate Cancer Group Study 7, Swedish Association for Urological Oncology 3 (2009) Quality of life in patients with locally advanced prostate cancer given endocrine treatment with or without radiotherapy: 4-year follow-up of SPCG-7/ SFUO-3, an open-label, randomised, phase III trial. Lancet Oncol 10:370-80

17. Robson A, Scrutton F, Wilkinson L, MacLeod F (2010) The risk of suicide in cancer patients: a review of the literature. Psychooncology 19:1250-1258

18. Anguiano L, Mayer DK, Piven ML, Rosenstein D (2012) A literature review of suicide in cancer patients. Cancer Nurs 35:E14-E26

19. Llorente MD, Burke M, Gregory GR et al (2005) Prostate cancer: a significant risk factor for late-life suicide. Am J Geriatr Psychiatry 13: 195-201

20. Fall K, Fang F, Mucci LA et al (2009) Immediate risk for cardiovascular events and suicide following a prostate cancer diagnosis: prospective cohort study. PLoS Med 6:e1000197

21. van Leeuwen PJ, Schröder FH (2010) Risk factors: increased risk of suicide after prostate cancer diagnosis. Nat Rev Urol 7:369-370

22. Carlsson S, Sandin F, Fall K, Lambe M, Adolfsson J, Stattin P, BillAxelson A (2013) Risk of suicide in men with low-risk prostate cancer. Eur J Cancer 49(7):1588-1599

23. Fang F, Keating NL, Mucci LA, Adami HO, Stampfer MJ, Valdimarsdóttir U, Fall K (2010) Immediate risk of suicide and cardiovascular death after a prostate cancer diagnosis: cohort study in the United States. J Natl Cancer Inst 102:307-314

24. Spoletini I, Gianni W, Caltagirone C, Madaio R, Repetto L, Spalletta G (2011) Suicide and cancer: where do we go from here? Crit Rev Oncol Hematol 78:206-219

25. Fang F, Fall K, Mittleman MA, Sparén P, Ye W, Adami HO, Valdimarsdóttir U (2012) Suicide and cardiovascular death after a cancer diagnosis. N Engl J Med 366:1310-1318

26. Bill-Axelson A, Garmo H, Lambe M, Bratt O, Adolfsson J, Nyberg U, Steineck G, Stattin P (2010) Suicide risk in men with prostatespecific antigen-detected early prostate cancer: a nationwide population-based cohort study from PCBaSe Sweden. Eur Urol 57: 390-395

27. Fransson P (2008) Quality of life for members of Swedish Prostate Cancer Patient Associations. Cancer Nurs 31(1):23-31

28. The Swedish Prostate Cancer Federation. http://www. prostatacancerforbundet.se/subPage1 .asp?nodeid=105435. Accessed 20 Sep 2013.

29. Kopp RP, Marshall LM, Wang PY, Bauer DC, Barrett-Connor E, Parsons JK, for the Osteoporotic Fractures in Men (MrOS) Research Group (2013) The burden of urinary incontinence and urinary bother among elderly prostate cancer survivors. Eur Urol 64(4):672-9

30. Sanda MG, Dunn RL, Michalski J, Sandler HM, Northouse L, Hembroff L, Lin X, Greenfield TK, Litwin MS, Saigal CS, Mahadevan A, Klein E, Kibel A, Pisters LL, Kuban D, Kaplan I, Wood D, Ciezki J, Shah N, Wei JT (2008) Quality of life and satisfaction with outcome among prostate-cancer survivors. N Engl J Med 358:1250-1261

31. Yiou R, Ebrahiminia V, Mouracade P, Lingombet O, Abbou C (2013) Sexual quality of life in women partnered with men using intracavernous alprostadil injections after radical prostatectomy. J Sex Med 10(5):1355-1362

32. Korfage IJ, Essink-Bot ML, Janssens AC, Schröder FH, de Koning $\mathrm{HJ}$ (2006) Anxiety and depression after prostate cancer diagnosis and treatment: 5-year follow-up. Br J Cancer 94:1093-1098

33. Holland JC, Alici Y (2010) Management of distress in cancer patients. J Support Oncol 8:4-12

34. Artherholt SB, Fann JR (2012) Psychosocial care in cancer. Curr Psychiatry Rep 14:23-29

35. Kunkel EJ, Bakker JR, Myers RE, Oyesanmi O, Gomella LG (2000) Biopsychosocial aspects of prostate cancer. Psychosomatics 41:85-94

36. De Sousa A, Sonavane S, Mehta J (2012) Psychological aspects of prostate cancer: a clinical review. Prostate Cancer Prostatic Dis 15: $120-127$

37. Bill-Axelson A, Garmo H, Nyberg U, Lambe M, Bratt O, Stattin P, Adolfsson J, Steineck G (2011) Psychiatric treatment in men with prostate cancer - results from a nation-wide, population-based cohort study from PCBaSe Sweden. Eur J Cancer 47:2195-2201

38. Fann JR, Ell K, Sharpe M (2012) Integrating psychosocial care into cancer services. J Clin Oncol 30:1178-1186

39. O'Connell H, Chin AV, Cunningham C, Lawlor BA (2004) Recent developments: suicide in older people. BMJ 329:895-899

40. Couper J, Bloch S, Love A, Macvean M, Duchesne GM, Kissane D (2006) Psychosocial adjustment of female partners of men with prostate cancer: a review of the literature. Psychooncology 15:937-953

41. Mellqvist M, Wiktorsson S, Joas E, Ostling S, Skoog I, Waern M (2011) Sense of coherence in elderly suicide attempters: the impact of social and health-related factors. Int Psychogeriatr 3:986-993

42. Cooke L, Gotto J, Mayorga L, Grant M, Lynn R (2013) What do I say? Suicide assessment and management. Clin J Oncol Nurs 17:E1-E7

43. McDowell ME, Occhipinti S, Ferguson M, Dunn J, Chambers SK (2010) Predictors of change in unmet supportive care needs in cancer. Psychooncology 19:508-516 